\title{
Periodontics in Nepal: Where Have We Reached?
}

\author{
Dr. Shaili Pradhan, ${ }^{1}$ Dr. Pramod Kumar Koirala ${ }^{1}$ \\ ${ }^{1}$ Periodontology and Oral Implantology Unit, Department of Dental Surgery, \\ National Academy of Medical Sciences, Bir Hospital, Kathmandu, Nepal.
}

\begin{abstract}
Periodontics is that speciality of dentistry which encompasses the prevention, diagnosis, and treatment of diseases of supporting and surrounding tissues of the teeth or their substitutes; the maintenance of health, function and aesthetics of these structures and tissues; and the replacement of lost teeth and supporting structures by grafting or implantation of natural or synthetic devices and materials. The quality field of Periodontics started in Nepal after 1999. The postgraduate studies in Periodontology and Oral Implantology have been running for a decade. Specialists in significant numbers are providing services throughout the country. Scientific researches and academic activities have been organised. Nepalese Society of Periodontology and Oral Implantology (NSPOI) has become a forum that is gaining recognition in the nation and on a global scale with the successful organisation of annual conferences, annual clinical meetings, postgraduate conventions and participations in international conferences since its establishment in 2014. The journal of the society (JNSPOI) is being regularly published since 2017. Societies in India and abroad have expressed good wishes and have contributed to the society regularly.

Keywords: History; Nepal; oral implantology; periodontology.
\end{abstract}

\section{INTRODUCTION}

Periodontal disease is defined as the chronic inflammatory diseases of bacterial aetiology that affect the toothsupporting soft and hard tissues. Gingivitis and periodontitis, are among the most prevalent diseases of humankind, with severe periodontitis being the sixth most prevalent disease worldwide, affecting nearly 800 million individuals. ${ }^{1}$ Even though it is largely preventable, periodontal disease remains a major public health issue in all countries around the world. Periodontal disease is one of the most common noncommunicable diseases of mankind in the world due to poor oral hygiene, smoking, stress, alcohol and systemic diseases. Periodontal disease shares many risk factors with other non-communicable diseases (NCDs) and can adequately be addressed through a common risk factor approach (CRFA). Periodontal disease is both preventable and treatable through adequate prevention and treatment strategies. ${ }^{2}$

Untreated periodontitis leads to tooth loss and, with it, masticatory, phonetic, aesthetic and social impairment; periodontitis is also associated with various co-morbidities like diabetes. ${ }^{3}$ The direct and indirect costs of periodontitis are substantial. ${ }^{4}$

\section{Correspondence:}

\section{Dr. Shaili Pradhan}

Periodontology and Oral Implantology Unit, Department of Den tal Surgery, National Academy of Medical Sciences, Bir Hospital, Kathmandu, Nepal.

email: shaili_p@yahoo.com

\section{Citation}

Pradhan S, Koirala PK. Periodontics in Nepal: Where Have We Reached? J Nepal Soc Perio Oral Implantol. 2019;3(5):38-9.
Prevalence of periodontal problem is high in Nepal. It occupies the second place among the oral health problems in our country. Due to the lower socio-economic status of the general population, regular oral health care has not been given priority, majority of people in rural area are away from qualified personnel and standard treatment. ${ }^{5}$

Along with the education and growing knowledge and experiences people are getting quality services in dentistry with specialists.

\section{POSTGRADUATE EDUCATION IN PERIODONTICS}

The field of Periodontics has taken shape after the postgraduate (PG) studies started in National Academy of Medical Sciences (NAMS) Bir Hospital under the co-ordination of the First Periodontist of Nepal, Dr. Shaili Pradhan. Dr. Ranjita Shrestha (2009-2012) was the first postgraduate student in NAMS. The seven batches have successfully completed under the guidance of Professor (Prof.) Dr. Shaili Pradhan with the production of 11 postgraduates, Master of Dental Surgery (MDS) in Periodontology and Oral Implantology.

The second Periodontist of Nepal Dr. Rita Singh is a successful private practitioner and is immediate past president of NSPOI.

Peoples Dental College has run PG program regularly since 2010 under the preceptor Prof. Dr. Surendra Man Shrestha with the production of five batches of PGs under the affiliation of Tribhuvan University. Prof. Dr. Surendra Man Shrestha is one of the pioneers of Periodontics in Nepal. He is heading the NSPOI team currently as the third president of NSPOI. 
B.P. Koirala Institute of Health Sciences (BPKIHS) has been running PG program in Periodontology and Oral Implantology since September 2011. The College of Dental Surgery, BPKIHS has come into existence on August 1999 as a pioneer of Dental Education in Nepal. Prof. Dr. Shiva Lal Sharma is the head of the department of Periodontics and preceptor of MDS Periodontology and Oral Implantology.

Universal College of Medical Sciences was established in the year 1998 in the western region of Nepal. It is located in Rupandehi district and 15 kilometers away from the birth place of Buddha, Lumbini. It has got the recognition of being an important and pioneer institution of the country where medical and dental courses are offered. It started MDS courses in 2010.

Kathmandu University School of Medical Sciences (KUSMS) has started PG program in Periodontology and Oral Implantology under the able guidance of Associate Professor Dr. Manoj Humagain.

Kantipur Dental College Teaching Hospital and Research Center (KDC-THRC) was established in 2007 with an aim to provide quality dental education and service in Nepal. It is the first dental college of Kathmandu University. It has established department of Periodontology and Oral Implantology under Associate Prof. Dr. Bhageshwar Dhami and postgraduate program started since 2018.

\section{PROFESSIONAL SOCIETY: NSPOI}

Nepalese Society of Periodontology and Oral Implantology (NSPOI) has become a forum that is gaining recognition in the nation and worldwide with the successful organisation of annual conferences, annual clinical meetings, postgraduate conventions and participations in international conferences.

Nepalese Society of Periodontology and oral Implantology (NSPOI), a non profit organisation of all the periodontist was founded on 8 th January 2014. NSPOI aims to promote periodontal and peri-implant tissue health in Nepal. It is heading ahead with the purpose to improve the awareness regarding Periodontology and Oral Implantology in the general public and to conduct relevant programs to keep updated regarding latest technologies on regular basis.
Table 1. Presidents of NSPOI

\begin{tabular}{|l|l|}
\hline Dr. Shaili Pradhan & 2014-2017 (Founder President) \\
\hline Dr. Rita Singh & $2017-2019$ \\
\hline Dr. Surendra Man Shrestha & $2019-2021$ \\
\hline
\end{tabular}

Table 2. The founder members of NSPOI

\begin{tabular}{|l|}
\hline Dr. Shaili Pradhan \\
\hline Dr. Rita Singh \\
\hline Dr. Surendra Man Shrestha \\
\hline Dr. Durga Pun \\
\hline Dr. Shiva Lal Sharma \\
\hline Dr. Sameer Aryal \\
\hline Dr. Manoj Humagin \\
\hline Dr. Bhageshwar Dhami \\
\hline Dr. Priti Shrestha \\
\hline Dr. Junima Rajkarnikar \\
\hline Dr. Ameena Pradhan \\
\hline Dr. Dhirendra Kumar Giri \\
\hline Dr. Ranjita Shrestha. \\
\hline
\end{tabular}

NSPOI has successfully organised five annual conferences, six clinical meets and five PG conventions with common efforts of executives and 36 life members.

Journal of the society of NSPOI (JNSPOI) is the major development in the field of Nepalese Periodontics in which specialists and researchers can publish their works. NSPOI has brought four issues of Journal of Nepalese Society of Periodontology and Oral Implantology (JNSPOI): Jan-June 2017 Volume 1 No. 1 to July-December 2018 Volume 2 No. 2. This is a medium of dissemination of information and recognition to authors. Research activities and publications have become regular practices.

\section{CONCLUSION}

Knowledge and best practices in this field are constantly changing with new research and experience broadening our understanding. In the coming days more and more people will get quality of services with the growing number of periodontists. NSPOI has become one of the most active dental subspeciality society performing various activities and timely publications.

\section{REFERENCES}

1. Kassebaum N, Smith A, Bernabé E, Fleming T, Reynolds A, Vos T, et al. Global, regional, and national prevalence, incidence, and disability-adjusted life years for oral conditions for 195 countries, 1990-2015: a systematic analysis for the global burden of diseases, injuries, and risk factors. J Dent Res. 2017;96(4):380-7.

2. Sheiham A, Watt RG. The common risk factor approach: a rational basis for promoting oral health. Community Dent Oral Epidemiol. 2000;28(6):399-406.

3. Tonetti MS, Jepsen S, Jin L, Otomo-Corgel J. Impact of the global burden of periodontal diseases on health, nutrition and wellbeing of mankind: A call for global action. J Clin Periodontol. 2017;44(5):456-62.

4. Righolt A, Jevdjevic M, Marcenes W, Listl S. Global-, regional-, and country-level economic impacts of dental diseases in 2015. J Dent Res. 2018;97(5):501-7.

5. Pradhan S, Bhat MK. Assessment of periodontal status of rural Nepalese population using the community periodontal index. J Nepal Dent Assoc. 2009;10(2):97-104. 